\title{
BETAS V CHARACTERISTICS: DO STOCK CHARACTERISTICS \\ ENHANCE THE INVESTMENT OPPORTUNITY SET IN U.K. STOCK RETURNS?
}

Jonathan Fletcher

Key words: Linear factor models, conditional models, stock characteristics, Bayesian test

JEL classification: G12

The author is from the University of Strathclyde.

Very helpful comments received from an anonymous reviewer.

This draft: April 2018

Address correspondence to Professor J. Fletcher, Department of Accounting and Finance, University of Strathclyde, 199 Stenhouse Building, Cathedral Street, Glasgow, G4 0QU, United Kingdom, phone: +44 (0) 141548 4963, fax: +44 (0) 141552 3547, email: j.fletcher@strath.ac.uk 


\title{
BETAS V CHARACTERISTICS: DO STOCK CHARACTERISTICS \\ ENHANCE THE INVESTMENT OPPORTUNITY SET IN U.K. STOCK RETURNS?
}

\begin{abstract}
I use the Bayesian approach of Wang(1998) to examine if stock characteristics or factor models make a significant incremental contribution to the investment opportunity set in U.K. stock returns. The paper finds that both stock characteristics and factor models make a significant incremental contribution to the investment opportunity set for unconstrained portfolio strategies. No short selling constraints eliminates the incremental contribution of factor models but the incremental contribution of stock characteristics remains significant, whether unconditional or conditional factor models used. My study suggests that stock characteristics make the dominant contribution to the investment opportunity set of U.K. stock returns.
\end{abstract}




\section{Introduction}

A central prediction of linear factor models, such as the Capital Asset Pricing Model (CAPM) of Sharpe(1964), Lintner(1965) and Mossin(1966), is that only systematic risk explains the cross-sectional differences in expected stock returns. However a number of studies during the past forty years find that stock characteristics ${ }^{1}$, such as size (Banz(1981)), book-to-market (BM) ratio (Fama and French(1992)), and momentum (Jegadeesh and Titman(1993)) among others, have a significant relation with cross-sectional stock returns even after adjusting for systematic risk. The interpretation of this empirical evidence is controversial where some argue that using a correct risk model would eliminate the significant predictive ability of stock characteristics (e.g. Fama and French $(1993,1996))$ and other studies argue that the role of characteristics is robust (e.g. Daniel and Titman(1997)) perhaps due to biases in investor psychology such as overreaction ${ }^{2}$.

A number of recent studies have started to examine the performance of factor models using individual stocks within the two-pass cross-sectional regression framework of Fama and MacBeth(1973). A partial list includes Chordia, Subrahmanyam and Tong(2014), Chorida, Goyal

${ }^{1}$ Excellent surveys of the cross-sectional puzzles and other issues in asset pricing include Subrahmanyam(2010), Cochrane(2011), Goyal(2012), and Nagel(2013). Harvey, Liu and Zhu(2016) find that empirical research has identified over 300 variables that are linked to stock returns.

2 Lin and Zhang(2013) question the whole relevance of the debate between betas and characteristics and whether this issue can ever be fully resolved. Kozak, Nagel and Santosh(2017) also point out the debate between betas and characteristics using reduced form factor models cannot answer whether pricing is rational or not. 
and Shanken(2015), Gagliardinia, Ossola and Scaillet(2016), Ang, Liu and Schwarz(2017), Raponi, Robotti and Zaffaroni(2017). Jegadeesh, Noh, Pukthuangthong, Roll and Wang(2017), Kim and Skoulakis(2018), and Chaieb, Langlois and Scaillet(2018) among others. The use of individual securities avoids the problems of using test portfolios such as the data snooping bias of Lo and MacKinlay(1990) and the sensitivity of results to the choice of the portfolio grouping approach used (Ahn, Conrad and Dittmar(2009), Lewellen, Nagel and Shanken(2010)). A major challenge in these studies is the Errors-in-Variables (EIV) bias since the betas used in the crosssectional regression have estimation error, which affects both the coefficients and standard errors in the cross-sectional regressions (Shanken(1992)).

Chordia, Goyal and Shanken(2015) use the two-pass cross-sectional regression approach to examine the relative contributions of both factor betas and stock characteristics to the crosssectional variation in expected excess returns. An alternative approach based on Fama and French(2015b) can be used to examine whether either stock characteristics or factor models make a significant incremental contribution to the investment opportunity set beyond that of either the corresponding factor models or stock characteristics. The essence of the Fama and French approach, applied to this application, is to examine the increase in Sharpe (1966) performance (DSharpe) of adding quintile portfolios formed using expected excess returns estimates from both factor models and stock characteristics to a benchmark investment universe of quintile portfolios formed from expected excess return ${ }^{3}$ from either the factor model or characteristics model. The

\footnotetext{
${ }^{3}$ Fama and French(2015b) find that focusing only on stock characteristics, that characteristics can have large Fama and MacBeth(1973) $t$-statistics and yet have no significant incremental
} 
attraction of the Fama and French approach is that the impact of portfolio constraints can be considered.

In this study, I examine whether stock characteristics and factor models make a significant incremental contribution to the investment opportunity set in U.K. stock returns. I use the Bayesian approach of Wang(1998) to estimate and evaluate the statistical significance of the DSharpe measure. The Bayesian approach is straightforward to implement and can easily include no short selling constraints. I examine the robustness of the results using an alternative bootstrap approach. I use the same set of stock characteristics as in Chordia et al(2015). The characteristics include size, BM, momentum, profitability, and asset growth. I use a similar set of factor models to Chordia et al. The factor models include the capital asset pricing model (CAPM), the three-factor model of Fama and French(1993), the four-factor model of Carhart(1997), the five-factor model of Fama and French(2015a,2016), a six-factor model which is the five-factor model plus the momentum factor (Fama and French(2017)), and the four-factor model similar to Hou, Xue and Zhang(2015). I consider both unconditional and conditional factor models.

There are four main findings in my study. First, both stock characteristics and unconditional factor models make a significant incremental contribution to the investment opportunity set using unconstrained portfolio strategies. The magnitude of the incremental contribution is a lot higher for the characteristics model. Second, no short selling eliminates the incremental contribution of unconditional factor models but the incremental contribution of stock characteristics remains significant. Third, the performance of the factor models improves using

contribution to the investment opportunity set in U.S. stock returns in the presence of no short selling constraints. 
conditional factor models. The incremental contribution of stock characteristics reduces and the incremental contribution of factor models usually increases. However no short selling constraints eliminates all the incremental contribution of the conditional factor models. Fourth, using a more stringent benchmark based on the optimal mean-variance portfolios in the presence of conditioning information (Hansen and Richard(1987), Ferson and Siegel(2001, 2009)) in the benchmark universe, all of the incremental contribution of factor models disappears even using unconstrained portfolio strategies but characteristics remain significant. My results suggest that stock characteristics make the dominant contribution to the investment opportunity set in U.K. stock returns.

My study makes three main contributions to the literature. First, I complement the recent study of Chordia et al(2015) by examining a different market and using a different approach to evaluate the impact of stock characteristics relative to factor models. Second, I complement the recent studies by Fama and French(2015b), Lewellen(2015), and Fletcher(2017) by examining the incremental contribution of stock characteristics to factor models rather than just focusing on stock characteristics. My study differs from Fama and French in that I use the Bayesian approach and evaluate the statistical significance of the incremental contribution of stock characteristics in the presence of no short selling constraints. Third, I extend the prior empirical evidence of linear factor models in U.K. stock returns e.g. Strong and Xu(1997), Antoniou, Garrett and Priestley(1998), Fletcher(2001), Al-Horani, Pope and Stark(2003), Gao and Huang(2008), Gregory and Michou(2009), Gregory, Tharyan and Christidis(2013), and Davies, Fletcher and Marshall(2015) among others by considering the incremental contribution of both stock characteristics (factor models) to the investment opportunity set beyond factor (characteristics) models. 
My paper is organized as follows. Section II presents the empirical methods. Section III describes the data used in my study. Section IV reports the empirical results and the final section concludes.

\section{Research Method}

Linear factor models, such as the CAPM, predict that there is an exact linear relation between expected excess returns and the corresponding $\mathrm{K}$ factor betas such that:

$$
\mathrm{E}\left(\mathrm{r}_{\mathrm{i}}\right)=\Sigma_{\mathrm{k}=1}{ }^{\mathrm{K}} \beta_{\mathrm{ik}} \gamma_{\mathrm{k}} \quad \text { for } \mathrm{i}=1, \ldots, \mathrm{N}
$$

where $r_{i}$ is the excess returns (over the risk-free return) of asset $i, \beta_{i k}$ is the beta of asset $i$ relative to factor $\mathrm{k}, \gamma_{\mathrm{k}}$ is the factor risk premium for factor $\mathrm{k}, \mathrm{K}$ is the number of factors in the model, and $\mathrm{N}$ is the number of risky assets. Equation (1) is the unconditional version of the linear factor models. Conditional factor models allow the betas and factor risk premiums to vary through time as a function of lagged information variables.

One of the most popular approaches to evaluate linear factor models is to use the two-pass cross-sectional regression approach of Fama and MacBeth(1973) ${ }^{4}$. In this study, I evaluate the role of stock characteristics relative to factor models using a similar approach to Fama and French(2015b) by examining the incremental contribution of stock characteristics to the investment opportunity set. Fama and French point out that large Fama and MacBeth(1973) $t$ statistics on the stock characteristics do not imply that the characteristics have a corresponding large impact on the average return spreads from portfolio sorts based on fitted expected returns from the monthly cross-sectional regressions. In addition, stock characteristics might have little

\footnotetext{
${ }^{4}$ Kan and Robotti(2012) and Gospodinov and Robotti(2013) provide excellent recent reviews of the two-pass cross-sectional regression approach.
} 
impact on the investment opportunity set when investors are not able to short sell or can short sell but restricted when short selling costs are prohibitive.

Fama and French $(2015 b)^{5}$ evaluate the incremental contribution of stock characteristics to the investment opportunity set by examining the increase in Sharpe(1966) performance of the tangency portfolio from adding quintile portfolios formed by expected excess returns from a larger characteristic-based model to a benchmark investment universe of quintile portfolios formed using a smaller characteristic-based model. I adapt the approach of Fama and French to examine the incremental contribution of stock characteristics to the investment opportunity set beyond that provided by linear factor models. I also consider the incremental contribution of linear factor models to the investment opportunity set beyond that provided by stock characteristics. In this setup, the benchmark investment universe is either quintile portfolios formed by expected excess returns from a linear factor model or quintile portfolios formed from a stock characteristics model. Quintile portfolios formed by expected excess returns from a factor model and characteristics model is then added to the corresponding benchmark investment universe to form the augmented investment universe.

I form expected excess returns for individual stocks using factor models and stock characteristics separately. I use both unconditional and conditional factor models. For unconditional factor models, I estimate the expected excess return each month as:

$$
\mathrm{E}\left(\mathrm{r}_{\mathrm{it}+1}\right)=\Sigma_{\mathrm{k}=1}^{\mathrm{K}} \beta_{\mathrm{ik}} \mathrm{r}_{\mathrm{k}}
$$

\footnotetext{
${ }^{5}$ Fama and French(2015b) only evaluate the incremental contribution of the size, BM, and momentum characteristics relative to the other two characteristics.
} 
where $r_{i t+1}$ is the excess return on stock $i$ at time $t+1, \beta_{i k}$ is the factor beta of asset $i$ relative to factor $\mathrm{k}$, and $\mathrm{r}_{\mathrm{k}}$ is the average excess returns of the factor.

When factors are portfolio returns, the factor premiums are given by the time-series average excess returns of the factor (Shanken(1992)). The betas are estimated from the time-series regression:

$$
\mathrm{r}_{\mathrm{it}+1}=\alpha_{\mathrm{i}}+\Sigma_{\mathrm{k}=1} \mathrm{~K}^{\mathrm{ik}} \mathrm{r}_{\mathrm{kt}+1}+\mathrm{e}_{\mathrm{it}+1}
$$

where $\mathrm{r}_{\mathrm{kt}+1}$ is the excess return of factor $\mathrm{k}$ at time $\mathrm{t}+1$, $\mathrm{e}_{\mathrm{it}+1}$ is a random error term at time $\mathrm{t}+1$, and $\beta_{\mathrm{ik}}$ is the unconditional beta of asset i relative to factor $\mathrm{k}$. I estimate the betas for each stock using all the available time-series return observations, with a minimum number of return observations being set to 60 months. This approach is similar to the recent studies by Gagliardini et al(2016), Harvey and Liu(2018), and Chaieb et al(2018) among others. The attraction of this approach is that it avoids the Errors-in-Variables (EIV) problem in the factor risk premiums from the estimation error in betas ${ }^{6}$. A recent study by Sarisoy, de Goeig and Werker(2017) show that the estimation error in expected excess returns estimates is lower from unconditional factor models when factor premiums are set equal to sample mean factor excess returns. The additional benefit is that the asymptotic distribution of expected excess returns estimates are not affected by small beta problems, which affects the asymptotic distribution of the factor premium estimates (see Burnside(2016), Bryzgalova(2016) among others).

\footnotetext{
${ }^{6}$ Recent studies developing alternative ways of adjusting factor risk premium estimates due to the EIV problem from the cross-sectional regression of individual stocks include Chordia et al(2015), Jegadeesh et al(2017), Raponi et al(2017), and Gagliardini et al(2016) among others.
} 
I also estimate expected excess returns of each stock using conditional factor models allowing for both time-varying conditional betas and conditional factor premiums. I estimate the expected excess return each month as:

$$
\mathrm{E}\left(\mathrm{r}_{\mathrm{it}+1}\right)=\Sigma_{\mathrm{k}=1}{ }^{\mathrm{K}} \beta_{\mathrm{ikt}} \mathrm{r}_{\mathrm{kt}}
$$

where $\beta_{\mathrm{ikt}}$ is the conditional beta of stock $\mathrm{i}$ at time $\mathrm{t}$, and $\mathrm{r}_{\mathrm{kt}}$ is the conditional factor premium at time t. I model the conditional betas and conditional factor premiums following a similar approach to Gagliardini et al(2016), where both conditional betas and conditional factor premiums are a linear function of lagged information variables (see also Shanken(1990), Ferson and Harvey(1991), and Avramov and Chordia(2006) among others). The conditional beta function can be estimated as in equation (3), where scaled factor excess returns are added to the regression given by the factor excess returns multiplied by the corresponding lagged information variables (see Ferson and Scahdt(1996)). The conditional betas of a given factor are then given by the coefficients from the regression multiplied by the lagged information variables ${ }^{7}$. The conditional factor premiums are calculated as the fitted values from predictive regressions of the excess factor returns on a constant and the lagged information variables.

I estimate expected excess returns using stock characteristics using the Fama and MacBeth(1973) cross-sectional regression approach. For each month of the sample period the following cross-sectional regression is run:

$$
\mathrm{r}_{\mathrm{it}+1}=\gamma_{0 \mathrm{t}+1}+\Sigma_{\mathrm{m}=1}{ }^{\mathrm{M}} \gamma_{\mathrm{mt}+1} \mathrm{Z}_{\mathrm{mt}}+\mathrm{u}_{\mathrm{it}+1}
$$

\footnotetext{
${ }^{7}$ The one difference with Gagliardini et al(2016) is that I do not model the conditional betas as a function of stock characteristics in addition to common lagged information variables.
} 
where $r_{i t+1}$ is the excess return on asset $i$ at time $t+1, z_{m t}$ is the value of the mth stock characteristic of asset $i$ at time $t$, and $u_{i t+1}$ is a random error term of asset $i$ at time $t+1$. The expected excess returns are given by:

$$
\mathrm{E}\left(\mathrm{r}_{\mathrm{it}+1}\right)=\Sigma_{\mathrm{m}=1}{ }^{\mathrm{M}} \gamma_{\mathrm{m}} \mathrm{Zmt}_{\mathrm{m}}
$$

where $\gamma_{\mathrm{m}}$ are the time-series averages of the monthly $\gamma_{\mathrm{mt}+1}$ coefficients, and $\gamma_{\mathrm{m}}$ can be defined as the characteristic premiums. Estimating expected excess returns using the Fama and MacBeth(1973) cross-sectional regression approach is used in a number of recent studies such as Fama and French(2006,2015b), Lewellen(2015), and Clarke(2016) among others. Fama and French point out that using full sample slopes has much greater precision compared to using rolling window estimates. Likewise if the portfolios are formed using monthly $\gamma_{\mathrm{mt}+1}$ coefficients, then most of the spread in portfolio returns will be due to unexpected returns and not due to expected return patterns.

To form the quintile portfolios, I use the following approach. At the start of each month, all stocks are ranked on the basis of the expected excess return from the factor model, stock characteristics model, and the combined factor model and characteristics model and grouped into quintile portfolios. I then calculate the monthly value weighted (VW) and equal weighted (EW) portfolio excess returns for each quintile portfolio. Where a security has missing return data during the month due to temporary suspension or death, I code the missing returns to zero as in Liu and Strong(2008). I correct for the delisting bias of Shumway(1997) by assigning a $-100 \%$ return if

\footnotetext{
${ }^{8}$ Plyakha, Uppal and Vilkov(2016) find that the use of EW or VW portfolios can have a significant impact on a number of asset pricing tests.
} 
the death is deemed valueless, using the information in the London Share Price Database (LSPD) provided by London Business School, as in Dimson, Nagel and Quigley(2003).

Define $\mathrm{N}$ as the number of risky assets in the benchmark investment universe, which can either be quintile portfolios formed by expected excess returns from the factor model or the stock characteristics model. An augmented investment universe is created by adding the quintile portfolios formed using the combined expected excess returns from the factor model and the characteristics model. The number of risky assets in the augmented investment universe is $2 \mathrm{~N}$. Define $\mathrm{x}$ as the $(2 \mathrm{~N}, 1)$ vector of optimal weights in the augmented investment universe, and $\mathrm{x}_{\mathrm{b}}$ is the $(2 \mathrm{~N}, 1)$ vector of optimal weights in the benchmark investment universe, where the first $\mathrm{N}$ cells are zero and the second $\mathrm{N}$ cells are the optimal weights of the $\mathrm{N}$ risky assets in the benchmark investment universe. The performance measure used for the incremental contribution of stock characteristics or factor models to the investment opportunity set is given by:

$$
\text { DSharpe }=\theta^{*}-\theta_{b}
$$

where $\theta^{*}=x^{\prime} \mathrm{u} /\left(\mathrm{x}^{\prime} \mathrm{Vx}\right)^{1 / 2}, \theta_{\mathrm{b}}=\mathrm{xb}^{\prime} \mathrm{u} /\left(\mathrm{x}_{\mathrm{b}}{ }^{\prime} \mathrm{V} \mathrm{x}_{\mathrm{b}}\right)^{1 / 2}, \mathrm{u}$ is a $(2 \mathrm{~N}, 1)$ vector of expected excess returns, and $\mathrm{V}$ is a $(2 \mathrm{~N}, 2 \mathrm{~N})$ covariance matrix. The DSharpe measure captures the increase in Sharpe performance in adding the quintile portfolios formed using the factor model and characteristics models to the benchmark investment universe. If the stock characteristics or factor models make no incremental contribution to the investment opportunity set, then DSharpe $=0$. By comparing the magnitude of the DSharpe measures, we can determine whether factor models or stock characteristics make the dominant incremental contribution to the investment opportunity set. I 
estimate the DSharpe measures for the case where unrestricted short selling is allowed and for the case where no short selling is allowed ${ }^{9}$ in the risky assets.

I use the Bayesian approach of Wang $(1998)^{10}$ to estimate the DSharpe measure and evaluate statistical significance. This approach is also applicable when no short selling is allowed in the risky assets. Traditional tests of mean-variance efficiency in the presence of no short selling constraints includes Basak, Jagannathan and Sun(2002) and De Roon, Nijman and Werker(2001). Li, Sarkar and Wang(2003) argue that the Bayesian approach has a number of advantages over the asymptotic tests of Basak et al and De Roon et al. First, the Bayesian approach incorporates the uncertainty of finite samples into the posterior distribution. Second, the Bayesian approach is easier to implement and can incorporate a wide range of portfolio constraints and performance measures. Third, in the presence of no short selling constraints the asymptotic tests rely on a firstorder linear approximation but the Bayesian approach uses the exact nonlinear function.

The analysis assumes that the $2 \mathrm{~N}$ asset excess returns have a multivariate normal distribution $^{11}$ and the expected excess returns $\mathrm{u}$ and covariance matrix $\mathrm{V}$ both have a noninformative prior. Define $u_{s}$ and $V_{s}$ as the sample moments of the expected excess returns and

\footnotetext{
${ }^{9}$ All portfolios on the efficient frontier have the same Sharpe performance. I select the optimal portfolios assuming a risk aversion level of 3 as in Tu and Zhou(2011).

${ }^{10}$ Recent applications of the Bayesian approach include Hodrick and Zhang(2014) and Liu(2016) in tests of international portfolio diversification.

${ }^{11}$ Assuming multivariate normality can be viewed as a working approximation in monthly returns. Grauer and Hakannson(1993) and Best and Grauer(2011) find mean-variance portfolios are close to the optimal portfolios from power utility functions over short return horizons.
} 
covariance matrix, and $\mathrm{r}$ as the $(\mathrm{T}, 2 \mathrm{~N})$ matrix of excess returns of the risky assets. The posterior probability density function is given by:

$$
\mathrm{p}(\mathrm{u}, \mathrm{V} \mid \mathrm{r})=\mathrm{p}\left(\mathrm{u} \mid \mathrm{V}, \mathrm{u}_{\mathrm{s}}, \mathrm{T}\right) \bullet \mathrm{p}\left(\mathrm{V} \mid \mathrm{V}_{\mathrm{s}}, \mathrm{T}\right)
$$

where $\mathrm{p}\left(\mathrm{u} \mid \mathrm{V}, \mathrm{u}_{\mathrm{s}}, \mathrm{T}\right)$ is the conditional distribution of a multivariate normal $\left(\mathrm{u}_{\mathrm{s}},(1 / \mathrm{T}) \mathrm{V}\right)$ distribution and $\mathrm{p}\left(\mathrm{V} \mid \mathrm{V}_{\mathrm{s}}, \mathrm{T}\right)$ is the marginal posterior distribution that has an inverse Wishart(TV, T-1) distribution (Zellner(1971)).

I use the Monte Carlo method of Wang(1998) to approximate the posterior distribution of the DSharpe measure. First, a random $\mathrm{V}$ matrix is drawn from an inverse Wishart $\left(\mathrm{TV}_{\mathrm{s}}, \mathrm{T}-1\right)$ distribution. Second, a random $u$ vector is drawn from a multivariate normal $\left(\mathrm{u}_{\mathrm{s}},(1 / \mathrm{T}) \mathrm{V}\right)$ distribution. Third, given the $\mathrm{u}$ and $\mathrm{V}$ from steps 1 and 2, the DSharpe measure is estimated from equation $(7)^{12}$. Fourth, steps 1 to 3 are repeated 1,000 times as in Hodrick and Zhang(2014) to generate the approximate posterior distribution of the DSharpe measure. The average value of the posterior distribution of the DSharpe measure provides the average increase in Sharpe performance in adding the quintile portfolios formed using the factor model and characteristics model to the benchmark investment universe. I use the 5\% percentile value of the DSharpe measure to assess the statistical significance of whether the average DSharpe measure $=0$ (Hodrick and Zhang(2014)). If the 5\% percentile value of the DSharpe measure exceeds zero, I reject the null hypothesis that the stock characteristics or factor models make no incremental contribution to the investment opportunity set.

${ }^{12}$ If the optimal portfolios lie on the inefficient side of the mean-variance frontier, I set the corresponding Sharpe performance to zero. 
To examine the robustness of using the Bayesian approach, I also run a bootstrap approach $^{13}$ when the benchmark universe is formed from the expected excess returns from the factor models. I estimate the actual difference in Sharpe performance between the augmented and benchmark investment universes. I then simulate the empirical distribution of the DSharpe measure under the null hypothesis that stock characteristics do not make a significant incremental contribution to the investment opportunity set beyond the factor models. To illustrate for the unconditional factor models, I use the following approach ${ }^{14}$. First, for each individual stock I estimate equation (3) and save the residuals. Second, I estimate the factor betas imposing the restriction that the alphas in equation (3) are equal to zero. Third, I resample, with replacement, $\mathrm{T}$ observations of the factors, characteristics, residuals, and risk-free returns, and calculate the simulated excess returns of individual stocks as the factor betas multiplied by the average simulated factor excess returns plus the residuals. Fourth, I then run the tests to get the simulated difference in Sharpe performance between the augmented and benchmark investment universes. Fifth, I repeat steps 2 to 41,000 times. The empirical $p$ value is given as the proportion of times that the simulated DSharpe measures are larger than the actual DSharpe measure.

\section{Data}

My sample includes all U.K. stocks between July 1983 and December 2016. All of the data is collected from LSPD unless otherwise specified. I use the one-month Treasury Bill return as the risk-free asset (collected from LSPD and Datastream). I exclude foreign companies,

\footnotetext{
${ }^{13}$ I thank the reviewer for suggesting this test.

${ }^{14}$ Chou and Zhou(2006) provide an excellent review of bootstrap approaches to test portfolio efficiency.
} 
secondary shares, and investment trusts ${ }^{15}$. I also exclude companies in months where their market value is below $£ 500,000$, and where the adjusted share price is below 50 pence. Jegadeesh et al(2017) and Chordia et al(2015) adopt similar exclusions. Given these restrictions, I am able to estimate expected excess returns from the unconditional factor models of 2,474 companies.

I consider the linear factor models as in Chordia et al(2015) as well as the four-factor model of Hou, Xue and Zhang(2015). Details of the construction of the factor models are included in the Appendix. The models include:

\section{CAPM}

This model is a single-factor model that uses the excess returns of the U.K. stock market index (Mkt) as the proxy for aggregate wealth.

2. Fama and French(1993) (FF)

The FF model is a three-factor model. The factors are the excess return on the market index and two zero-cost portfolios that capture the size (SMB) and value/growth (HML) effects in stock returns.

3. Carhart(1997) $)^{16}$

The Carhart model is a four-factor model. The factors are the three factors in the FF model and a zero-cost portfolio that captures the momentum effect (WML) in stock returns.

\footnotetext{
${ }^{15}$ Investment trusts are the same as U.S. closed-end funds.

${ }^{16}$ Maio and Santa-Clara(2012) find that both the Fama and French(1993) and Carhart(1997) models are the most consistent with ICAPM restrictions across a wide range of different multifactor models. In contrast, Barbalau, Robotti and Shanken(2015) find that it is difficult to reject ICAPM restrictions for multifactor models.
} 


\section{Fama and French(2015a) (FF5)}

The FF5 model is a five-factor model. The factors include the factors in the FF model and two zero-cost portfolios that capture the profitability (RMW) (see also Novy-Marx(2012)) and investment growth (CMA) effects in stock returns. I use the SMB factor from the FF5 model in both the FF3 and FF6 models.

\section{Fama and French(2017) (FF6)}

This model is a six-factor model, which includes the FF5 model and the WML factor. Fama and French(2016) find in their examination of anomalies in U.S. stock returns, that the momentum factor is only important when the test assets are size/momentum portfolios.

6. Hou, Xue and Zhang(2015) (HXZ)

This model is a four-factor model. The factors include the excess returns on the market index and three zero-cost portfolios that capture the size (ME), profitability (ROE), and investment growth (IA) factors.

I use the same set of stock characteristics as Chordia et al(2015). The characteristics include size, BM, momentum, profitability, and asset growth characteristics. Fama and French(2015b) only consider the size, BM, and momentum characteristics in their study. Lewellen(2015) finds that including additional characteristics beyond size, BM, and momentum only has a marginal impact on the predictive ability of stock characteristics in cross-sectional U.S. stock returns. Details of the characteristics are included in the Appendix.

Panel A of Table 1 reports summary statistics of the factors in the FF6 and HXZ models. The summary statistics in panel A includes the mean and standard deviation of the excess factor returns $(\%)$, and the $t$-statistic of the null hypothesis that the average factor excess returns equals zero. Panel B reports the average coefficients and corresponding $t$-statistics from the monthly 
Fama and MacBeth(1973) regressions of the excess returns of individual stocks on a constant and the five stock characteristics.

Table 1 here

Panel A of Table 1 shows that most of the factors have significant positive mean excess returns. The exceptions are the two size factors (SMB and ME), and the profitability RMW factor. The WML factor has the largest mean excess return at $0.907 \%$. The two investment factors (CMA and IA) have large positive mean excess returns. The most noticeable result is that the mean excess return of the ROE factor is considerably higher the $\mathrm{RMW}^{17}$ factor and is statistically significant. This result stems from the way the ROE factor is formed compared to the RMW factor. The ROE factor is formed monthly compared to annual for RMW and is based on a triple-sort process rather than a double-sort process. It is only for the CMA, WML, and IA factors that have $t$-statistics larger than 3, the cut-off $t$ statistic recommended by Harvey, Liu and Zhu(2016) to control for multiple testing.

Panel B of Table 1 shows that all five stock characteristics have significant characteristic premiums. The signs of the premiums are consistent with prior research. The momentum characteristic has the largest characteristic premium at $1.110 \%$ followed by the profitability

\footnotetext{
${ }^{17}$ The mean excess return on the RMW factor is even lower if the operating profitability measure of Fama and French(2015a) is used.
} 
characteristic at $0.708 \%{ }^{18}$. The $t$-statistics of the characteristic premiums are considerably higher than the $t$-statistics of the factor premiums in panel A of Table 1. Fama and French(2015b) point out that large $t$-statistics in the Fama and MacBeth(1973) regressions do not imply that the characteristics will make a significant incremental contribution to the investment opportunity set of investors.

I use two lagged information variables when modelling the conditional betas and factor risk premiums. I use the lagged annualized dividend yield on the market index and the lagged one-month Treasury Bill return similar to Ferson and Schadt(1996) and are also used by Ferson and Siegel(2009).

\section{Empirical Results}

I begin my empirical analysis by testing the incremental contribution of the stock characteristics and unconditional factor models to the investment opportunity set using the unconstrained portfolio strategies. Table 2 reports summary statistics of the posterior distribution of the annualized DSharpe measures ${ }^{19}$ where the benchmark investment universe is formed using expected excess returns from the unconditional factor models (panel A) and from the stock characteristics model (panel B). The results are reported for the VW portfolios first and then for the EW portfolios. The summary statistics include the mean, standard deviation, fifth percentile (5\%), and the median. The final two columns of the Table include the sum of the average short

\footnotetext{
${ }^{18}$ I rerun the Fama and MacBeth(1973) regressions using the operating profitability measure. The corresponding profitability characteristic premium is $0.474 \%$ with a $t$-statistic of 0.95 , which highlights the weaker profitability effect using this measure.

19 The annualized Sharpe measure is given by the monthly DSharpe measure* $12^{1 / 2}$.
} 
positions in the benchmark (Bench) investment universe and augmented (Augment) investment universe. Panel $\mathrm{C}$ reports the sample DSharpe measures and the empirical $\mathrm{p}$ values using the bootstrap approach.

Table 2 here

Panel A of Table 2 shows that stock characteristics make a significant incremental contribution to the investment opportunity set using the unconstrained portfolio strategies. This result holds across all factor models and using both VW and EW portfolios. The annualized mean DSharpe measures range between 0.643 (Carhart) and 0.896 (CAPM) for the VW portfolios and between 1.443 (FF6) and $1.726\left(\right.$ FF5) ${ }^{20}$. All of the mean DSharpe measures are highly significant at the $5 \%$ percentile. The median DSharpe measures are close to the mean DSharpe measures. The increase in Sharpe performance is a lot stronger using the EW portfolios. This result stems from the fact that stock characteristics have a stronger relation with returns in smaller companies (Fama and French(2008), Lewellen(2015)). Panel C shows that using the bootstrap approach yields similar results to the Bayesian approach, which suggests that our findings are robust using the Bayesian approach.

The optimal portfolios underlying the increase in Sharpe performance in panel A of Table 2 do require large short positions. The sum of average short positions for the VW portfolios in the augmented investment universe ranges between -5.400 (Carhart) amd -10.390 (FF). There is a

\footnotetext{
${ }^{20}$ Using the operating profitability measure in the FF5 model yields similar performance to that in Table 2 .
} 
substantial increase in the sum of average short positions using the EW portfolios. This result stems from the fact that using the EW portfolios leads to a wider cross-sectional spread in average excess returns. These short positions imply that long-only investors will not be able to achieve this superior performance and even investors who can short sell, much of the superior performance will disappear due to short selling costs (Fama and French(2015b)).

Panel B of Table 2 shows that unconditional factor models make a significant incremental contribution to the investment opportunity set beyond the stock characteristics. However there is a striking difference in the magnitude of the annualized DSharpe measures in panel B compared to panel A. The mean DSharpe measures range between 0.101 (FF6) and 0.244 (CAPM) for the VW portfolios and between 0.057 (CAPM) and 0.131 (Carhart) for the EW portfolios. All of the mean DSharpe measures are significant at the 5\% percentile. The mean DSharpe measures are lower for the EW portfolios here again due to the stronger impact that stock characteristics have among smaller companies. As with the VW and EW portfolios in panel A, the optimal weights underlying the increase in Sharpe performance in panel B do require large short positions.

Table 2 shows that stock characteristics make by far the dominant contribution to the investment opportunity set. The unconditional factor models make only a marginal contribution beyond the stock characteristics model. This finding is consistent with Chordia et al(2015) who find that stock characteristics make the dominant contribution to capturing the cross-sectional variation in expected excess returns compared to unconditional beta models. I next examine the impact of no short selling constraints on the incremental contribution of the both stock characteristics and unconditional factor models to the investment opportunity set. Table 3 reports the summary statistics of the posterior distribution of the Sharpe measure for the constrained portfolio strategies. 
Table 3 here

Table 3 shows that no short selling constraints has a dramatic effect on the mean and volatility of the DSharpe measures. There is a sharp drop in both the mean and volatility of the DSharpe measures. This pattern is similar to Wang(1998) and Li et al(2003). The drop in the mean DSharpe measures highlights that the incremental contribution of stock characteristics and factor models is reduced and is consistent with studies that show no short selling constraints can hurt the mean-variance performance of trading strategies such as De Roon et al(2001), Fama and French(2015b), and Briere and Szafarz(2017). The drop in the volatility of the DSharpe measures is due to the lower estimation risk when short selling constraints are imposed (Frost and Savarino(1988) and Jagannathan and $\mathrm{Ma}(2003))^{21}$.

Panel A of Table 3 shows that no short selling constraints substantially reduces the incremental contribution of stock characteristics to the investment opportunity but the incremental contribution remains significant. The annualized mean DSharpe measures range between 0.253 (HXZ) and 0.382 (FF6) for the VW portfolios and between 0.487 (CAPM) and 0.539 (FF) for the EW portfolios. All of the mean DSharpe measures are significant at the 5\% percentile. The gap between the mean DSharpe measures between VW and EW portfolios is a lot narrower compared to the unconstrained portfolio strategies. Panel B of Table 3 shows in contrast to panel A, that all

${ }^{21}$ Basak et $\mathrm{al}(2002)$ find that the standard errors of their mean-variance inefficiency measure increases in the presence of no short selling constraints. They point out that this result is due to the linear approximation being less reliable with no short selling constraints. 
of the incremental contribution of unconditional factor models disappears in the presence of no short selling constraints. The mean DSharpe measures are essentially zero. This finding holds for all factor models and using either VW or EW portfolios.

Tables 2 and 3 suggest that both stock characteristics and unconditional factor models make a significant incremental contribution to the investment opportunity set when short selling is allowed. However no short selling eliminates all of the incremental contribution of unconditional factor models and suggests that stock characteristics are the dominant driver of the investment opportunity set. These results are consistent with the importance of stock characteristics in explaining cross-sectional stock returns in the recent studies by Chordia et al(2015) and Jegadeesh et al(2017) among others in U.S. stock returns. The impact of no short selling constraints on the incremental contribution is also consistent with Fama and French(2015b) and Fletcher(2017). I next examine the use of conditional factor models and I repeat the tests of Tables 2 and 3. Tables 4 and 5 provide the summary statistics of the posterior distribution of the DSharpe measures for the unconstrained (Table 4) and constrained (Table 5) portfolio strategies.

Table 4 here

Table 5 here

Panel A of Table 4 shows that stock characteristics make a significant incremental contribution to the investment opportunity set beyond conditional factor models using the unconstrained portfolio strategies. This result holds regardless of the linear factor model used and for both VW and EW portfolios. The mean DSharpe measures are large in economic terms and 
all are significant at the $5 \%$ percentile ${ }^{22}$. The optimal portfolios underlying the increase in Sharpe performance do require substantial leverage. The minimum sum of the average short positions is -2.825 (CAPM) for the VW portfolios and -5.156 for the EW portfolios. As in panel A of Table 2, the mean DSharpe measures are larger using the EW portfolios consistent with the stronger relation between stock characteristics and returns among smaller companies (Fama and French(2008)). Comparing the mean DSharpe measures to panel A of Table 2, there is a substantial drop in the mean DSharpe measures suggesting that conditional factor models do a better job in capturing the investment opportunity set compared to unconditional factor models.

Panel B of Table 4 shows that conditional factor models make a significant incremental contribution to the investment opportunity set beyond stock characteristics when there are no portfolio constraints beyond the budget constraint. The mean DSharpe measures are substantially lower than in panel A of Table 4, with the exception of the CAPM with the VW portfolios. All of the mean DSharpe measures are significant at the $5 \%$ percentile. In most cases, the mean DSharpe measures are higher for the conditional factor models compared to the unconditional factor models in panel B of Table 2, although the differences are marginal. Again the optimal portfolios do require a lot of leverage. Although the conditional factor models seem to perform better than the unconditional factor models, stock characteristics continue to make the dominant contribution to the investment opportunity set using unconstrained portfolio strategies.

\footnotetext{
${ }^{22}$ I also run the tests using the bootstrap approach and in the main the results are similar to panel A of Table 4. The sample DSharpe measures are significant for all models at the $10 \%$ level using the EW portfolios and for all models, except the CAPM and FF6 models, at the 10\% level using VW portfolios.
} 
Table 5 shows that when no short selling constraints are imposed, there is again a sharp drop in the mean and volatility of the DSharpe ratios. Panel A shows that no short selling constraints substantially reduces the incremental contribution of stock characteristics to the investment opportunity set. This pattern is most noticeable for the EW portfolios, where the maximum mean DSharpe measure is 0.219 (FF) compared to maximum mean DSharpe measure in Table 4 as $0.978(\mathrm{FF})$. Most of the mean DSharpe measures in panel A of Table 5 remain significant at the 5\% percentile. However for the conditional CAPM model, the mean DSharpe measures for the VW and EW portfolios are tiny and no longer significant.

Comparing the mean DSharpe measures for the constrained portfolio strategies in panel A of Table 5 to panel A of Table 3, provides some support for the improved performance of conditional factor models relative to unconditional factor models. The mean DSharpe measures in panel A of Table 5 are in most cases reduced, especially for the EW portfolios. In contrast to panel A of Table 5, no short selling constraints eliminates all the incremental contribution of conditional factor models to the investment opportunity set. The mean DSharpe measures are tiny and none are significant at the $5 \%$ percentile.

Tables 4 and 5 suggest that although conditional factor models reduces the incremental contribution of stock characteristics to the investment opportunity set, the presence of no short selling constraints continues to eliminate the incremental contribution of factor models to the investment opportunity set. My final test examines whether stock characteristics and factor models make a significant incremental contribution to the investment opportunity set using a more stringent benchmark. The benchmark I use is the optimal portfolio from the quintile portfolios in the benchmark investment universe that maximizes the unconditional mean-variance (UMV) trade-off in the presence of conditioning information (Hansen and Richard(1987), Ferson and 
Siegel(2001) $)^{23}$. This benchmark provides a more stringent test of the incremental contribution of stock characteristics or factor models as the optimal mean-variance portfolios in the presence of conditioning information expands the efficient frontier compared to the fixed-weight efficient frontier (Ferson and Siegel(2009), Penaranda(2016)). I follow the approach of Ferson and Siegel $(2001,2009)$ to conduct these tests.

The first step of the approach is to estimate the UMV portfolio from the quintile portfolios in the benchmark investment universe using the optimal portfolio weight solutions in Ferson and Siegel(2001). I estimate the conditional expected returns of the portfolios using the fitted values from the predictive regressions of the portfolio returns on a constant and the two lagged information variables and assume the conditional covariance matrix is constant given by the sample covariance matrix of the residuals from the predictive regression as in Ferson and Siegel(2009) $)^{24}$. I then calculate the UMV portfolio returns each month. The incremental contribution of stock characteristics or factor models can be evaluated from the time-series regression in equation (3) of the excess returns of the quintile portfolios formed using expected excess returns using the factor model and characteristics and the excess returns of the UMV portfolio as the benchmark. Under the null hypothesis of no incremental contribution, the $\mathrm{N} \alpha$ 's

${ }^{23}$ I thank the reviewer for suggesting this topic.

${ }^{24}$ Ferson and Siegel(2001) show that the optimal UMV portfolio weights are conservative in the presence of extreme signals from the conditioning information. This response stem from the fact that the goal of the UMV portfolios is to maximize the unconditional mean-variance trade-off rather than the conditional mean-variance trade-off. 
will be jointly equal to zero (Gibbons, Ross and Shanken(1989), Ferson and Siegel(2009)). I test this hypothesis using a Wald test, and using a bootstrap approach similar to Ferson and Siegel.

Table 6 reports the tests of whether stock characteristics make a significant incremental contribution to the investment opportunity set using the UMV benchmark formed from the quintile portfolios using expected excess returns using unconditional factor models in panel A and conditional models in panel B. Table 6 reports the annualized DSharpe measure, the Wald test statistic and corresponding $\mathrm{p}$ value, and the empirical $\mathrm{p}$ value from the bootstrap approach. I also run the reverse tests of whether the factor models provide a significant incremental contribution to the investment opportunity set relative to the UMV benchmark formed from the quintile portfolios using expected excess returns from the characteristics model. In this case, neither unconditional or conditional factor models provide a significant incremental contribution to the investment opportunity set. This result suggests that the incremental contribution of the factor models using unconstrained portfolio strategies disappears using the more stringent UMV benchmark.

Table 6 here

Panel A of Table 6 shows that stock characteristics continue to provide a significant incremental contribution to the investment opportunity set even in the presence of the optimal UMV portfolio from the benchmark investment universe. This result holds for both VW and EW portfolios and for all factor models. The magnitude of the DSharpe measures are large in economic terms and all are significant using the Wald test with both asymptotic and empirical $p$ values essentially zero. As with the earlier results, the magnitude of the incremental contribution of stock characteristics is larger when using the EW portfolios as reflected in much higher DSharpe 
measures. Comparing the DSharpe measures to panel $\mathrm{C}$ of Table 2, shows that there is a sharp drop in the magnitude of the DSharpe measures when evaluating the incremental contribution relative to the UMV portfolio from the benchmark universe. This pattern reflects the tougher hurdle that the use of UMV portfolio implies ${ }^{25}$.

When conditional factor models are used to form the quintile portfolios in panel B of Table 6 , there is a drop in the magnitude of the incremental contribution of stock characteristics. The DSharpe measures in panel B are considerably lower than in panel A. This pattern again highlights the improved performance of conditional factor models relative to unconditional factor models. However all of the DSharpe measures remain significant using both asymptotic and empirical $p$ values, except for the CAPM using the VW portfolios. For the EW portfolios, all of the DSharpe measures are significant at the $10 \%$ level. Table 6 shows that the significant incremental contribution of stock characteristics remains robust even in the presence of a more stringent benchmark.

\section{Conclusions}

This study uses the Bayesian approach of Wang(1998) to examine whether stock characteristics and factor models make a significant incremental contribution to the investment opportunity set in U.K. stock returns. There are four main findings in my study. First, I find that both stock characteristics and unconditional factor models make a significant incremental contribution to the investment opportunity set using unconstrained portfolio strategies. Stock

\footnotetext{
${ }^{25}$ Ferson and Siegel(2009) find that hedge fund indexes enhance the mean-variance frontier when using fixed-weight frontiers of test assets but the significant performance disappears when comparing the hedge fund indexes to the UMV frontier of the test assets.
} 
characteristics provide a much higher incremental contribution than the factor models, which is consistent with Chordia et al(2015) who find that stock characteristics make the dominant relative contribution to explaining the cross-sectional variation in U.S. stock returns. The incremental contribution of stock characteristics is higher using EW portfolios, which is consistent with the impact that the choice of EW or VW portfolios has on asset pricing tests as in Plyakha et al(2016) and the stronger relations between characteristics and returns for smaller companies (Fama and French(2008), Lewellen(2015)).

Second, no short selling constraints eliminates all of the incremental contribution of unconditional factor models to the investment opportunity sets. In contrast, the incremental contribution of stock characteristics remains significant. Although there is a large reduction in the mean DSharpe measures for the stock characteristics, they remain large in economic terms and statistically significant. The large impact of no short selling constraints on the incremental stock contribution of stock characteristics and factor models is consistent with Fama and French(2015b) and Fletcher(2017). This finding is also consistent with studies that find no short selling constraints hurts mean-variance performance of trading strategies, such as De Roon et al(2001), Li et al(2003), and Briere and Szafarz(2017).

Third, using conditional factor models improves the incremental contribution of factor models to the investment opportunity set and reduces the incremental contribution of stock characteristics for unconstrained portfolio strategies. However no short selling constraints eliminates the incremental contribution of conditional factor models. The incremental contribution of stock characteristics are further reduced, but the mean DSharpe measures remain significant except for the CAPM. 
Fourth, using the more stringent UMV benchmark of Ferson and Siegel(2001, 2009) to evaluate the incremental contribution of both factor models and stock characteristics shows that stock characteristics continue to provide a significant incremental contribution to the investment opportunity set. In contrast, the incremental contribution of both unconditional and conditional factor models disappears even for unconstrained portfolio strategies. The finding that the UMV portfolio is a more stringent benchmark is consistent with Ferson and Siegel(2009) in relation to hedge fund performance.

My results suggest that stock characteristics make the dominant contribution to the investment opportunity set in U.K. stock returns, especially in the presence of no short selling constraints. I have only used a small number of linear factor models and stock characteristics in my study. A broader range of linear factor models, such as Stambaugh and Yuan(2017), Fama and French(2017), Daniel, Hirshleifer and Sun(2018) and the inclusion of more stock characteristics could also be examined. The performance of the models could also be examined over different market states perhaps using the dummy variable approach of Ferson and Qian(2004). I leave an examination of these issues to future research. 


\section{Appendix}

\section{A) Stock Characteristics}

The market values and stock returns data are collected from the London Share Price Database (LSPD) provided by the London Business School. The accounting data is collected from Worldscope provided by Thomson Financial. The characteristics involving only accounting data are only calculated once a year. I assume that the monthly characteristic data, using only accounting data, between July of year $t$ to June of year $t+1$ are equal to the annual characteristic values calculated during year $\mathrm{t}-1$. This approach assumes that the accounting data from the fiscal year-end of the previous calendar year t-1 would be known to investors by the start of July in year t. All of the characteristic data is winsorized at the $1 \%$ and $99 \%$ levels as in Lewellen(2015). The characteristics are defined as follows:

1. Size

The size of the company is given by the monthly market values. I use the log of the monthly market values at the prior month-end to measure size. I set companies with zero market values to missing values.

2. Book-to-Market (BM) ratio

The monthly BM ratio is calculated using the book value of equity at the fiscal year-end (WC03501) during the previous calendar year divided by the prior month-end market value. I set companies with negative book values or zero market values to missing values. I use the log of the $\mathrm{BM}$ ratio in my analysis.

3. Momentum 
I calculate the momentum characteristic each month as the prior cumulative returns of the stock between months -12 to -2 . Companies must have continuous return observations during the past 12 months, otherwise the momentum characteristic is set to missing values.

4. Profitability

I use the gross profitability measure as in Novy-Marx(2013) and Sun, Wie and Xie(2014) defined as sales (WC01001) minus cost of goods sold (WC01051) divided by total assets (WC02999). I also use the operating profitability measure similar to Fama and French(2015a), which is defined as sales minus cost of goods sold minus interest expense on debt (WC01251) minus selling, general, administrative expenses (WC01101) divided by total assets.

5. Asset Growth

I calculate asset growth similar to Fama and French(2017) as the change in total assets between years $\mathrm{t}-1$ and $\mathrm{t}-2$ divided by total assets at year $\mathrm{t}-2$.

\section{B) Formation of the Factors in the Linear Factor Models}

To construct the market index, I use a similar approach to Dimson and Marsh(2001). At the start of each year between 1983 and 2016, I construct a value weighted portfolio of all stocks on LSPD by their market value at the start of the year. I calculate buy and hold monthly returns during the next year. I exclude companies with a zero market value. I correct the portfolio returns as described when forming the quintile portfolios, which I follow across all factors.

To form the SMB and HML factors I use a similar approach to Fama and French(2012). At the start of July year between 1983 and 2016, all stocks on LSPD are ranked separately by their market value at the end of June and by their BM ratio from the prior calendar year. The BM ratio is calculated using the book value of equity at the fiscal year-end during the previous calendar year from Worldscope and the year-end market value. Two size groups (Small and Big) are formed 
using a breakpoint of $90 \%$ by aggregate market capitalization where the Small stocks are the companies with smallest $10 \%$ by market value and the Big stocks are the companies with the largest $90 \%$ by market value ${ }^{26}$. Three BM groups (Growth, Neutral, and Value) are formed using break points of the $30^{\text {th }}$ and $70^{\text {th }}$ percentiles of the BM ratios of Big stocks. Six portfolios of securities are then constructed at the intersection of the size and BM groups ( $\mathrm{SG}, \mathrm{SN}, \mathrm{SV}, \mathrm{BG}$, $\mathrm{BN}, \mathrm{BV}$ ). The monthly buy and hold return for the six portfolios are then calculated during the next 12 months. The initial weights are set equal to the market value weights at the end of June. Companies with a zero market value, and negative book values are excluded.

The $\mathrm{SMB}_{\mathrm{BM}}$ factor is the difference in the average return of the three small firm portfolios (SG, SN, SV) and the average return of the three large firm portfolios (BG, BN, BV). The HML factor is the average of HMLs and HML $L_{B}$ where HMLs is the difference in portfolio returns of SV and $\mathrm{SG}$ and $\mathrm{HML}_{\mathrm{B}}$ is the difference in portfolio returns of $\mathrm{BV}$ and $\mathrm{BG}$. The $\mathrm{HML}_{\mathrm{S}}$ and $\mathrm{HML}_{\mathrm{B}}$ zero-cost portfolios capture the value effect in Small stocks and Big stocks respectively.

I form the WML factor using a similar approach to Fama and French(2012). At the start of each month between July 1983 and December 2016, all stocks on LSPD are ranked separately by their market value at the end of the previous month and on the basis of their cumulative return from months -12 to -2 . Two size groups (Small and Big) are formed as in the case of the size/BM portfolios. Three past return groups (Losers, Neutral, and Winners) are formed using break points of the $30^{\text {th }}$ and $60^{\text {th }}$ percentiles of the past returns of Big stocks. Six portfolios of securities are

${ }^{26}$ This approach is the same as Fama and French(2012). Dimson and Marsh(2001) also classify U.K. stocks in the largest $90 \%$ of market capitalization as High-Cap stocks. Stocks in the lowest $10 \%$ are defined as Low-Cap and Micro-Cap stocks. 
then constructed at the intersection of the size and momentum groups (SL, SN, SW, BL, BN, BW). The value weighted return for the six portfolios are then calculated during the next month. Companies with a zero market value, and less than 12 return observations during the past year are excluded from the portfolios.

The WML factor is the average of $\mathrm{WML}_{S}$ and $\mathrm{WML}_{\mathrm{B}}$ where $\mathrm{WML}$ is the difference in portfolio returns of SW and SL and $\mathrm{WML}_{\mathrm{B}}$ is the difference in portfolio returns of $\mathrm{BW}$ and $\mathrm{BL}$. The WMLs and WMLB zero-cost portfolios capture the momentum effect in Small stocks and Big stocks respectively.

To form the RMW and CMA factors, I use a similar approach to Fama and French(2015a). At the start of July each year between 1983 and 2016, I sort stocks separately by market value at the end of June and either by Gross Profitability (GP) or Investment Growth (Inv) from the prior calendar year. Inv is defined as the annual change in total assets divided by lagged total assets. Two size groups are formed as in the case of the size/BM portfolios. Three GP groups (Weak, Neutral, and Robust) are formed using break points of the $30^{\text {th }}$ and $70^{\text {th }}$ percentiles of the GP ratios of Big stocks and three Inv groups (Conservative, Neutral, and Aggressive) are formed using breakpoints of the $30^{\text {th }}$ and $70^{\text {th }}$ percentiles of the Inv ratios of Big stocks. Six portfolios are then formed of the intersection between the six size and GP groups (SW, SN, SR, BW, BN, BR) and the six size and Inv groups ( $\mathrm{SC}, \mathrm{SN}, \mathrm{SA}, \mathrm{BC}, \mathrm{BN}, \mathrm{BA})$. The monthly buy and hold return for the two groups of six portfolios are then calculated during the next 12 months. The initial weights are set equal to the market value weights at the end of June. Companies with a zero market value, and/or zero sales, zero costs of goods sold, and zero total assets are excluded from the size/GP portfolios. Companies with zero total assets are excluded from the size/Inv portfolios. 
The RMW factor is the average of RMW and $R M W_{B}$ where $R M W_{S}$ is the difference in portfolio returns of SR and $\mathrm{SW}$ and $\mathrm{RMW}_{\mathrm{B}}$ is the difference in portfolio returns of $\mathrm{BR}$ and $\mathrm{BW}$. The RMW and RMW $\mathrm{R}_{\mathrm{B}}$ zero-cost portfolios capture the profitability effect in Small stocks and Big stocks respectively. The CMA factor is the average of $\mathrm{CMA}_{\mathrm{S}}$ and $\mathrm{CMA}_{\mathrm{B}}$ where $\mathrm{CMAs}_{\mathrm{S}}$ is the difference in portfolio returns of $\mathrm{SC}$ and $\mathrm{SA}$ and $\mathrm{CMA}_{\mathrm{B}}$ is the difference in portfolio returns of $\mathrm{BC}$ and $\mathrm{BA}$. The $\mathrm{CMA}_{\mathrm{S}}$ and $\mathrm{CMA}_{\mathrm{B}}$ zero-cost portfolios capture the investment effect in Small stocks and Big stocks respectively. There are three size factors from the size/BM portfolios ( $\mathrm{SMB}_{\mathrm{BM}}$ ), size/GP portfolios $\left(\mathrm{SMB}_{\mathrm{GP}}\right)$, and size/Inv portfolios $\left(\mathrm{SMB}_{\mathrm{INV}}\right)$. The size factor in the Fama and French(2015a) five-factor model is the average of $\mathrm{SMB}_{\mathrm{BM}}, \mathrm{SMB}_{\mathrm{GP}}$, and $\mathrm{SMB}$ INV. I also form the factors in the Fama and French model using the operating profitability measure.

To form the ME, ROE, and IA factors of Hou et al(2015), I use the following approach. At the start of each month between July 1983 and December 2016, all stocks are ranked independently by size, Inv, and, and return on equity (ROE). Size is the market value at the end of the previous month. Inv for the July of year $t$ to June of year $t+1$ is the change in total assets in the calendar years of $\mathrm{t}-1$ and $\mathrm{t}-2$ divided by total assets in year $\mathrm{t}-2$. The ROE from the previous month is collected from Thomson Financial Datastream. Stocks are grouped into two size groups Small and Big using a breakpoint of $10 \%$ of aggregate market capitalization. Stocks are grouped into three ROE and Inv groups using breakpoints of 30\% and 70\% of the ROE and Inv measures of Big companies. I then form 18 portfolios at the intersection of the groups and value weighted portfolio returns are calculated for the next month. In addition to the existing exclusions, I also exclude financials here.

The ME factor is the difference between the average returns of nine small portfolios and the nine big portfolios. The IA factor is the difference between the average returns of the six low 
IA portfolios and the six high IA portfolios. The ROE factor is the difference between the average returns of the six high ROE portfolios and the six low ROE portfolios. 
Table 1 Summary Statistics of Factors and Fama and MacBeth(1973) Regressions

\begin{tabular}{lrrr}
\hline Panel A: & Mean & Standard Deviation & $t$-statistic \\
Factors & 0.434 & 4.185 & $2.07^{1}$ \\
Market & 0.015 & 2.945 & 0.10 \\
SMB & 0.300 & 2.552 & $2.35^{1}$ \\
HML & 0.145 & 2.018 & 1.44 \\
RMW & 0.411 & 1.896 & $4.34^{1}$ \\
CMA & 0.907 & 3.789 & $4.80^{1}$ \\
WML & 0.184 & 3.026 & 1.21 \\
ME & 0.360 & 2.444 & $2.95^{1}$ \\
ROE & 0.490 & 2.261 & $4.35^{1}$ \\
IA & & & \\
Panel B: & Coefficient & t-statistic & \\
Characteristics & 3.192 & $6.02^{1}$ & \\
Constant & -0.192 & $-4.80^{1}$ & \\
Size & 0.441 & $6.70^{1}$ & \\
BM & 1.110 & $5.83^{1}$ & \\
Momentum & 0.708 & $4.57^{1}$ & \\
Profitability & -0.489 & $-5.11^{1}$ & \\
Asset Growth & & & \\
\hline
\end{tabular}

${ }^{1}$ Significant at $5 \%$

The table reports summary statistics of the excess factor returns and Fama and MacBeth(1973) cross-sectional regressions between July 1983 and December 2016. The summary statistics in panel A include the mean and standard deviation (\%) of excess factor returns in the FF6 and HXZ models and the $t$-statistic of the null hypothesis that the average excess factor return equals zero. The factors in the FF6 model include the excess returns on the market index and zero-cost portfolios that capture the size (SMB), value/growth (HML), , profitability (RMW), asset growth (CMA), and momentum (WML) effects in stock returns. The factors in the HXZ model include zero-cost portfolios for size (ME), profitability (ROE), and asset growth (IA). Panel B reports the average coefficients and the corresponding $t$-statistics from the monthly Fama and MacBeth(1973) cross-sectional regressions of the excess returns of individual stocks on a constant and five stock characteristics. The characteristics include size, book-to-market (BM) ratio, momentum, profitability, and asset growth. 
Table 2 Posterior Distribution of the DSharpe Measure for Unconstrained Portfolio Strategies: Unconditional Factor Models

\begin{tabular}{|c|c|c|c|c|c|c|}
\hline \multicolumn{7}{|l|}{ Panel A: } \\
\hline \multicolumn{7}{|l|}{ Beta } \\
\hline VW & Mean & Std Dev & $5 \%$ & Median & Bench & Augment \\
\hline CAPM & 0.896 & 0.183 & 0.604 & 0.888 & -0.509 & -8.571 \\
\hline $\mathrm{FF}$ & 0.821 & 0.184 & 0.525 & 0.811 & -0.697 & -10.390 \\
\hline Carhart & 0.643 & 0.162 & 0.395 & 0.631 & -1.126 & -5.400 \\
\hline FF5 & 0.734 & 0.173 & 0.448 & 0.734 & -0.979 & -8.922 \\
\hline FF6 & 0.853 & 0.182 & 0.564 & 0.843 & -1.065 & -9.547 \\
\hline HXZ & 0.687 & 0.177 & 0.405 & 0.676 & -0.685 & -9.529 \\
\hline $\mathrm{EW}$ & Mean & Std Dev & $5 \%$ & Median & Bench & Augment \\
\hline CAPM & 1.647 & 0.209 & 1.303 & 1.645 & -2.919 & -15.640 \\
\hline $\mathrm{FF}$ & 1.682 & 0.207 & 1.341 & 1.677 & -1.802 & -13.649 \\
\hline Carhart & 1.449 & 0.200 & 1.120 & 1.453 & -3.028 & -12.681 \\
\hline FF5 & 1.726 & 0.216 & 1.378 & 1.731 & -2.152 & -17.353 \\
\hline FF6 & 1.443 & 0.200 & 1.113 & 1.440 & -2.608 & -15.196 \\
\hline HXZ & 1.560 & 0.207 & 1.223 & 1.554 & -0.614 & -13.958 \\
\hline \multicolumn{7}{|l|}{ Panel B: } \\
\hline \multicolumn{7}{|l|}{ Chars } \\
\hline VW & Mean & Std Dev & $5 \%$ & Median & Bench & Augment \\
\hline CAPM & 0.244 & 0.096 & 0.108 & 0.232 & -2.907 & -13.537 \\
\hline $\mathrm{FF}$ & 0.201 & 0.089 & 0.073 & 0.191 & -2.868 & -9.087 \\
\hline Carhart & 0.166 & 0.079 & 0.058 & 0.155 & -2.867 & -6.122 \\
\hline FF5 & 0.142 & 0.072 & 0.042 & 0.131 & -2.860 & -6.732 \\
\hline FF6 & 0.101 & 0.059 & 0.026 & 0.089 & -2.903 & -5.255 \\
\hline $\mathrm{HXZ}$ & 0.174 & 0.081 & 0.058 & 0.163 & -2.844 & -6.981 \\
\hline EW & Mean & Std Dev & $5 \%$ & Median & Bench & Augment \\
\hline CAPM & 0.057 & 0.035 & 0.013 & 0.050 & -6.069 & -7.651 \\
\hline $\mathrm{FF}$ & 0.092 & 0.051 & 0.025 & 0.084 & -5.987 & -12.539 \\
\hline Carhart & 0.131 & 0.062 & 0.045 & 0.123 & -5.977 & -14.695 \\
\hline FF5 & 0.067 & 0.039 & 0.015 & 0.059 & -5.996 & -9.420 \\
\hline FF6 & 0.082 & 0.044 & 0.026 & 0.075 & -6.003 & -11.194 \\
\hline HXZ & 0.098 & 0.054 & 0.027 & 0.089 & -5.987 & -10.816 \\
\hline \multirow[t]{2}{*}{ Panel C } & VW & & EW & & & \\
\hline & DSharpe & $\mathrm{p}$ value & DSharpe & $\mathrm{p}$ value & & \\
\hline CAPM & 0.890 & 0 & 1.651 & 0 & & \\
\hline $\mathrm{FF}$ & 0.821 & 0 & 1.706 & 0 & & \\
\hline Carhart & 0.633 & 0 & 1.467 & 0 & & \\
\hline FF5 & 0.738 & 0 & 1.763 & 0 & & \\
\hline FF6 & 0.881 & 0 & 1.457 & 0 & & \\
\hline HXZ & 0.690 & 0.001 & 1.602 & 0 & & \\
\hline
\end{tabular}


The table reports the summary statistics of the posterior distribution of the annualized DSharpe measure between July 1983 and December 2016 using unconstrained portfolio strategies for both VW and EW portfolios. The DSharpe measure is the increase in Sharpe performance in moving the optimal portfolio from the benchmark (Bench) investment universe to the optimal portfolio from the augmented (Augment) investment universe. The benchmark universe is either quintile portfolio excess returns formed using expected excess returns from unconditional factor models (panel A) or stock characteristics (panel B). The augmented universe includes the benchmark universe and quintile portfolios formed using expected excess returns from the unconditional factor models and characteristics model. The summary statistics include the mean, standard deviation (Std Dev), the fifth percentile (5\%), and the median of the posterior distribution of the DSharpe measures. The final two columns in panels A and B include the sum of the average short positions in the benchmark investment universe and the augmented investment universe. Panel C reports the sample annualized DSharpe measures when the benchmark universe includes the quintile portfolios formed from expected excess returns using the factor models, and the corresponding empirical $p$ values from a bootstrap approach. 
Table 3 Posterior Distribution of the DSharpe Measure for Constrained Portfolio Strategies: Unconditional Factor Models

\begin{tabular}{|c|c|c|c|c|}
\hline $\begin{array}{l}\text { Panel A: } \\
\text { Betas } \\
\text { VW }\end{array}$ & Mean & Std Dev & $5 \%$ & Median \\
\hline CAPM & 0.303 & 0.132 & 0.105 & 0.293 \\
\hline $\mathrm{FF}$ & 0.305 & 0.129 & 0.095 & 0.295 \\
\hline Carhart & 0.324 & 0.124 & 0.131 & 0.316 \\
\hline FF5 & 0.304 & 0.120 & 0.109 & 0.305 \\
\hline FF6 & 0.382 & 0.114 & 0.199 & 0.374 \\
\hline HXZ & 0.253 & 0.114 & 0.083 & 0.245 \\
\hline EW & Mean & Std Dev & $5 \%$ & Median \\
\hline CAPM & 0.487 & 0.109 & 0.298 & 0.493 \\
\hline $\mathrm{FF}$ & 0.539 & 0.090 & 0.381 & 0.546 \\
\hline Carhart & 0.529 & 0.073 & 0.411 & 0.529 \\
\hline FF5 & 0.535 & 0.082 & 0.389 & 0.544 \\
\hline FF6 & 0.537 & 0.073 & 0.414 & 0.538 \\
\hline HXZ & 0.529 & 0.073 & 0.399 & 0.528 \\
\hline $\begin{array}{l}\text { Panel B: } \\
\text { Chars } \\
\text { VW }\end{array}$ & Mean & Std Dev & $5 \%$ & Median \\
\hline CAPM & 0.007 & 0.016 & 0 & 0 \\
\hline $\mathrm{FF}$ & 0.000 & 0.003 & 0 & 0 \\
\hline Carhart & 0.000 & 0.003 & 0 & 0 \\
\hline FF5 & 0.001 & 0.006 & 0 & 0 \\
\hline FF6 & 0.006 & 0.014 & 0 & 0 \\
\hline HXZ & 0.000 & 0.003 & 0 & 0 \\
\hline EW & Mean & Std Dev & $5 \%$ & Median \\
\hline CAPM & 0 & 0 & 0 & 0 \\
\hline $\mathrm{FF}$ & 0 & 0 & 0 & 0 \\
\hline Carhart & 0 & 0 & 0 & 0 \\
\hline FF5 & 0 & 0 & 0 & 0 \\
\hline FF6 & 0 & 0 & 0 & 0 \\
\hline HXZ & 0 & 0 & 0 & 0 \\
\hline
\end{tabular}


The table reports the summary statistics of the posterior distribution of the annualized DSharpe measure between July 1983 and December 2016 using constrained portfolio strategies for both VW and EW portfolios. No short selling constraints are imposed on the risky assets. The DSharpe measure is the increase in Sharpe performance in moving the optimal portfolio from the benchmark (Bench) investment universe to the optimal portfolio from the augmented (Augment) investment universe. The benchmark universe is either quintile portfolio excess returns formed using expected excess returns from unconditional factor models (panel A) or stock characteristics (panel B). The augmented universe includes the benchmark universe and quintile portfolios formed using expected excess returns from the unconditional factor models and characteristics model. The summary statistics include the mean, standard deviation (Std Dev), the fifth percentile (5\%), and the median of the posterior distribution of the DSharpe measures. 
Table 4 Posterior Distribution of the DSharpe Measure for Unconstrained Portfolio Strategies: Conditional Factor Models

\begin{tabular}{|c|c|c|c|c|c|c|}
\hline $\begin{array}{l}\text { Panel A: } \\
\text { Betas } \\
\text { VW }\end{array}$ & Mean & Std Dev & $5 \%$ & Median & Bench & Augment \\
\hline CAPM & 0.160 & 0.086 & 0.042 & 0.150 & -0.815 & -2.825 \\
\hline FF & 0.576 & 0.161 & 0.322 & 0.569 & -1.205 & -4.686 \\
\hline Carhart & 0.324 & 0.118 & 0.146 & 0.313 & -1.733 & -3.848 \\
\hline FF5 & 0.681 & 0.173 & 0.398 & 0.678 & -1.021 & -7.400 \\
\hline FF6 & 0.337 & 0.118 & 0.154 & 0.328 & -1.062 & -3.755 \\
\hline HXZ & 0.597 & 0.166 & 0.345 & 0.593 & -1.194 & -5.754 \\
\hline EW & Mean & Std Dev & $5 \%$ & Median & Bench & Augment \\
\hline CAPM & 0.265 & 0.113 & 0.103 & 0.249 & -0.503 & -5.156 \\
\hline $\mathrm{FF}$ & 0.978 & 0.175 & 0.700 & 0.968 & -4.847 & -13.345 \\
\hline Carhart & 0.581 & 0.142 & 0.367 & 0.572 & -3.919 & -9.019 \\
\hline FF5 & 0.882 & 0.172 & 0.612 & 0.874 & -3.998 & -13.124 \\
\hline FF6 & 0.541 & 0.135 & 0.329 & 0.533 & -5.750 & -13.933 \\
\hline HXZ & 0.802 & 0.166 & 0.544 & 0.799 & -1.172 & -10.674 \\
\hline $\begin{array}{l}\text { Panel B: } \\
\text { Chars } \\
\text { VW }\end{array}$ & Mean & Std Dev & $5 \%$ & Median & Bench & Augment \\
\hline CAPM & 0.246 & 0.096 & 0.102 & 0.237 & -2.877 & -5.680 \\
\hline $\mathrm{FF}$ & 0.201 & 0.091 & 0.071 & 0.190 & -2.869 & -7.468 \\
\hline Carhart & 0.206 & 0.093 & 0.074 & 0.193 & -2.866 & -4.952 \\
\hline FF5 & 0.170 & 0.080 & 0.055 & 0.159 & -2.868 & -3.845 \\
\hline FF6 & 0.245 & 0.101 & 0.099 & 0.230 & -2.903 & -5.374 \\
\hline $\mathrm{HXZ}$ & 0.212 & 0.089 & 0.087 & 0.201 & -2.849 & -5.681 \\
\hline EW & Mean & Std Dev & $5 \%$ & Median & Bench & Augment \\
\hline CAPM & 0.097 & 0.052 & 0.027 & 0.089 & -6.027 & -9.707 \\
\hline $\mathrm{FF}$ & 0.107 & 0.054 & 0.034 & 0.098 & -5.970 & -10.192 \\
\hline Carhart & 0.143 & 0.065 & 0.053 & 0.133 & -5.981 & -11.464 \\
\hline FF5 & 0.108 & 0.055 & 0.031 & 0.100 & -5.989 & -9.381 \\
\hline FF6 & 0.107 & 0.056 & 0.030 & 0.099 & -6.009 & -8.373 \\
\hline HXZ & 0.085 & 0.048 & 0.021 & 0.077 & -5.993 & -7.863 \\
\hline
\end{tabular}


The table reports the summary statistics of the posterior distribution of the annualized DSharpe measure between July 1983 and December 2016 using unconstrained portfolio strategies for both VW and EW portfolios. The DSharpe measure is the increase in Sharpe performance in moving the optimal portfolio from the benchmark (Bench) investment universe to the optimal portfolio from the augmented (Augment) investment universe. The benchmark universe is either quintile portfolio excess returns formed using expected excess returns from conditional factor models (panel A) or stock characteristics (panel B). The augmented universe includes the benchmark universe and quintile portfolios formed using expected excess returns from the conditional factor models and characteristics model. The summary statistics include the mean, standard deviation (Std Dev), the fifth percentile (5\%), and the median of the posterior distribution of the DSharpe measures. The final two columns in panels A and B include the sum of the average short positions in the benchmark investment universe and the augmented investment universe. The conditional factor models assume that both conditional betas and factor premiums are a linear function of the lagged one month Treasury Bill return and lagged annualized dividend yield on the market index. 
Table 5 Posterior Distribution of the DSharpe Measure for Constrained Portfolio Strategies: Conditional Factor Models

\begin{tabular}{|c|c|c|c|c|}
\hline $\begin{array}{l}\text { Panel A: } \\
\text { Betas } \\
\text { VW }\end{array}$ & Mean & Std Dev & $5 \%$ & Median \\
\hline CAPM & 0.044 & 0.041 & 0 & 0.032 \\
\hline $\mathrm{FF}$ & 0.356 & 0.115 & 0.156 & 0.363 \\
\hline Carhart & 0.212 & 0.088 & 0.075 & 0.208 \\
\hline FF5 & 0.326 & 0.108 & 0.142 & 0.324 \\
\hline FF6 & 0.190 & 0.089 & 0.053 & 0.184 \\
\hline HXZ & 0.293 & 0.107 & 0.129 & 0.284 \\
\hline EW & Mean & Std Dev & $5 \%$ & Median \\
\hline CAPM & 0.003 & 0.009 & 0 & \\
\hline $\mathrm{FF}$ & 0.219 & 0.058 & 0.127 & 0.218 \\
\hline Carhart & 0.093 & 0.060 & 0.011 & 0.087 \\
\hline FF5 & 0.186 & 0.059 & 0.087 & 0.185 \\
\hline FF6 & 0.075 & 0.056 & 0.004 & 0.065 \\
\hline HXZ & 0.151 & 0.056 & 0.057 & 0.153 \\
\hline $\begin{array}{l}\text { Panel B: } \\
\text { Chars } \\
\text { VW }\end{array}$ & Mean & Std Dev & $5 \%$ & Median \\
\hline CAPM & 0.000 & 0.002 & 0 & \\
\hline $\mathrm{FF}$ & 0.033 & 0.039 & 0 & 0.019 \\
\hline Carhart & 0.062 & 0.052 & 0.000 & 0.052 \\
\hline FF5 & 0.025 & 0.032 & 0 & 0.012 \\
\hline FF6 & 0.069 & 0.058 & 0.000 & 0.055 \\
\hline HXZ & 0.026 & 0.034 & 0 & 0.013 \\
\hline EW & Mean & Std Dev & $5 \%$ & Median \\
\hline CAPM & 0 & 0 & & \\
\hline $\mathrm{FF}$ & 0.000 & 0.004 & 0 & 0 \\
\hline Carhart & 0.013 & 0.023 & 0 & 0.002 \\
\hline FF5 & 0.002 & 0.007 & 0 & 0 \\
\hline FF6 & 0.010 & 0.018 & 0 & 0.001 \\
\hline $\mathrm{HXZ}$ & 0.001 & 0.004 & 0 & 0 \\
\hline
\end{tabular}


The table reports the summary statistics of the posterior distribution of the annualized DSharpe measure between July 1983 and December 2016 using constrained portfolio strategies for both VW and EW portfolios. No short selling constraints are imposed on the risky assets. The DSharpe measure is the increase in Sharpe performance in moving the optimal portfolio from the benchmark (Bench) investment universe to the optimal portfolio from the augmented (Augment) investment universe. The benchmark universe is either quintile portfolio excess returns formed using expected excess returns from conditional factor models (panel A) or stock characteristics (panel B). The augmented universe includes the benchmark universe and quintile portfolios formed using expected excess returns from the conditional factor models and characteristics model. The summary statistics include the mean, standard deviation (Std Dev), the fifth percentile (5\%), and the median of the posterior distribution of the DSharpe measures. The conditional factor models assume that both conditional betas and factor premiums are a linear function of the lagged one month Treasury Bill return and lagged annualized dividend yield on the market index. 
Table 6 Incremental Contribution of Stock Characteristics Relative to the UMV Benchmark

\begin{tabular}{|c|c|c|c|c|}
\hline $\begin{array}{l}\text { Panel A: } \\
\text { Unc Factor } \\
\text { VW }\end{array}$ & DSharpe & Wald & pWald & $\begin{array}{r}\text { Empirical } p \\
\text { value }\end{array}$ \\
\hline CAPM & 0.565 & 48.623 & 0 & 0 \\
\hline FF & 0.480 & 35.964 & 0 & 0 \\
\hline Carhart & 0.363 & 23.058 & 0 & 0 \\
\hline FF5 & 0.336 & 22.018 & 0 & 0 \\
\hline FF6 & 0.507 & 35.824 & 0 & 0 \\
\hline $\mathrm{HXZ}$ & 0.262 & 17.809 & 0.003 & 0.006 \\
\hline EW & DSharpe & Wald & pWald & $\begin{array}{r}\text { Empirical } p \\
\text { value }\end{array}$ \\
\hline CAPM & 0.939 & 97.788 & 0 & 0 \\
\hline $\mathrm{FF}$ & 0.918 & 89.399 & 0 & 0 \\
\hline Carhart & 0.769 & 73.264 & 0 & 0 \\
\hline FF5 & 0.758 & 62.372 & 0 & 0 \\
\hline FF6 & 0.747 & 70.065 & 0 & 0 \\
\hline $\mathrm{HXZ}$ & 0.642 & 54.755 & 0 & 0 \\
\hline $\begin{array}{l}\text { Panel B: } \\
\text { Cond Factor } \\
\text { VW }\end{array}$ & DSharpe & Wald & pWald & $\begin{array}{r}\text { Empirical } p \\
\text { value }\end{array}$ \\
\hline CAPM & 0.107 & 5.747 & 0.331 & 0.384 \\
\hline $\mathrm{FF}$ & 0.315 & 18.257 & 0.002 & 0.003 \\
\hline Carhart & 0.201 & 13.232 & 0.021 & 0.022 \\
\hline FF5 & 0.255 & 15.774 & 0.007 & 0.009 \\
\hline FF6 & 0.209 & 14.073 & 0.015 & 0.020 \\
\hline HXZ & 0.276 & 18.091 & 0.002 & 0.004 \\
\hline EW & DSharpe & Wald & pWald & $\begin{array}{r}\text { Empirical } p \\
\text { value }\end{array}$ \\
\hline CAPM & 0.147 & 10.718 & 0.057 & 0.060 \\
\hline $\mathrm{FF}$ & 0.430 & 32.686 & 0 & 0 \\
\hline Carhart & 0.456 & 40.379 & 0 & 0 \\
\hline FF5 & 0.516 & 41.485 & 0 & 0 \\
\hline FF6 & 0.455 & 41.078 & 0 & 0 \\
\hline HXZ & 0.383 & 28.874 & 0 & 0 \\
\hline
\end{tabular}


The table reports the sample annualized DSharpe measure in moving from the optimal UMV portfolio formed from the benchmark investment universe to the optimal portfolio in the augmented universe between July 1983 and December 2016 for both VW and EW portfolios. The UMV portfolio from the benchmark universe is formed using either quintile portfolio excess returns formed from the expected excess returns from unconditional factor models (Unc Factor) (panel A) or conditional factor models (Cond Factor) (panel B). The augmented universe includes the UMV portfolio and quintile portfolios formed using expected excess returns from the factor models and characteristics model. The Wald and pWald columns are the Wald test statistics and corresponding $\mathrm{p}$ value are from the Wald test of zero alphas. The empirical $\mathrm{p}$ value comes from a similar bootstrap approach of Ferson and Siegel(2009). To calculate the UMV portfolio, it is assumed that the conditional expected returns of the quintile portfolios in the benchmark universe are the fitted values of the predictive regression of portfolio returns on a constant and the lagged information variables (lag one month Treasury Bill return and lag annualized dividend yield on the market index). The conditional covariance matrix is assumed constant and is given the sample covariance matrix of the residuals from the predictive regression. The conditional factor models assume that both conditional betas and factor premiums are a linear function of the lagged one month Treasury Bill return and lagged annualized dividend yield on the market index. 


\section{References}

Ahn, D.H., Conrad, J. and R.F. Dittmar, 2009, Basis assets, Review of Financial Studies, 22, 13431375.

Al-Horani, A, Pope, P.F. and A.W. Stark, 2003, Research and development activity and expected returns in the United Kingdom, European Finance Review, 7, 27-46.

Ang, A., Liu, J. and K. Schwarz, 2017, Using stocks or portfolios in tests of factor models, Working Paper, Columbia University.

Antoniou, A., Garrett, I. and R. Priestley, 1998, Macroeconomic variables as common pervasive risk factors and the empirical content of the arbitrage pricing theory, Journal of Empirical Finance $5,221-240$

Avramov, D. and T. Chordia, 2006, Asset pricing models and financial market anomalies, Review of Financial Studies, 19, 1000-1040

Banz, R.W., 1981, The relationship between return and market value of common stocks, Journal of Financial Economics, 9, 3-18.

Barbalau, A., Robotti, C. and J. Shanken, 2015, Testing inequality restrictions in multifactor assetpricing models, Working Paper, Emory University.

Basak, G., Jagannatha, R. and G. Sun, 2002, A direct test for the mean-variance efficiency of a portfolio, Journal of Economic Dynamics and Control, 26, 1195-1215.

Best, M.J. and R.R. Grauer, 2011, Prospect-theory portfolios versus power-utility and meanvariance portfolios, Working Paper, University of Waterloo.

Briere, M. and A. Szafarz, 2017, Factor investing: The rocky road from long-only to long-short, in E. Jurczenko (Ed), Factor Investing, Elsevier, forthcoming. 
Bryzgalova, S., 2016, Spurious factors in linear asset pricing models, Working Paper, Stanford University.

Burnside, C., 2016, Identification and inference in linear stochastic discount factor models with excess returns, Journal of Econometrics, 14, 295-330.

Carhart, M. M., 1997. Persistence in mutual fund performance. Journal of Finance, 52, 57-82.

Chaieb, I., Langlois, H. and O. Scaillet, 2018, Time-varying risk premia in large international equity markets, Working Paper, Swiss Finance Institute.

Chordia, T., Goyal, A. and J. Shanken, 2015, Cross-sectional asset pricing with individual stocks: Betas versus characteristics, Working Paper, Emory University.

Chou, P.H. and G. Zhou, 2006, Using bootstrap to test portfolio efficiency, Annals of Economics and Finance, 7, 217-249.

Chordia, T., Subrahmanyam, A. and Q. Tong, 2014, Have capital market anomalies attenuated in the recent era of high liquidity and trading activity, Journal of Accounting and Economics, 58, 4158.

Clarke, C., 2016, The level, slope and curve factor model for stocks, Working Paper, University of Connecticut.

Cochrane, J.H., 2011, Discount rates, Journal of Finance, 66, 1047-1108.

Daniel, K. and S. Titman, 1997, Evidence on the characteristics of cross-sectional variation in common stock returns, Journal of Finance, 52, 1-33.

Daniel, K., Hirshleifer, D. and L. Sun, 2018, Short- and long-horizon behavioral factors, Working Paper, Columbia University.

Davies, J.R., Fletcher, J. and A. Marshall, 2015, Testing index-based models in U.K. stock returns, Review of Quantitative Finance and Accounting, 45, 337-362. 
De Roon, F.A., Nijman, T.E. and B.J.M. Werker, 2001, Testing for mean-variance spanning with short sales constraints and transaction costs: The case of emerging markets,Journal of Finance, $56,721-742$.

Dimson, E. and P.R. Marsh, 2001, U.K. financial market returns 1955-2000, Journal of Business $74,1-31$

Dimson, P., Nagel, S. and G. Quigley, 2003, Capturing the value premium in the U.K. 1955-2001, Financial Analysts Journal, 5559, 35-45.

Fama, E.F. and K.R. French, 1992, The cross-section of expected stock returns, Journal of Finance, $47,427-465$.

Fama, E.F. and K.R. French, 1993, Common risk factors in the returns on stocks and bonds. Journal of Financial Economics 33, 3-56.

Fama, E.F. and K.R. French, 1996 Multifactor explanations of asset pricing anomalies, Journal of Finance, 51, 55-84.

Fama, E.F. and K.R. French, 2006, Profitability, investment, and average returns, Journal of Finance, 82, 491-518.

Fama, E.F. and K.R. French, 2008, Dissecting anomalies, Journal of Finance, 63, 1653-1678.

Fama, E.F. and K.R. French, 2012, Size, value, and momentum in international stock returns, Journal of Financial Economics, 105, 457-472.

Fama, E.F. and K.R. French, 2015a, A five-factor asset pricing model, Journal of Financial Economics, 116, 1-22.

Fama, E.F. and K.R. French, 2015b, Incremental variables and the investment opportunity set, Journal of Financial Economics, 117, 470-488. 
Fama, E.F. and K.R. French, 2016, Dissecting anomalies with a five-factor model, Review of Financial Studies, 29, 69-103.

Fama, E.F. and K.R. French, 2017, Choosing factors, Working Paper, University of Chicago.

Fama, E.F., and J.D. MacBeth, 1973, Risk, return, and equilibrium: Empirical tests, Journal of Political Economy, 71, 607-636.

Ferson, W.E. and C.R. Harvey, 1991, The variation in economic risk premiums, Journal of Political Economy, 99, 385-415.

Ferson, W.E. and M. Qian, 2004, Conditional performance evaluation revisited, Research Foundation Monograph, CFA Institute.

Ferson, W.E. and R. Schadt, 1996, Measuring fund strategy and performance in changing economic conditions, Journal of Finance, 51, 425-462.

Ferson, W.E. and A.F. Siegel, 2001, The efficient use of conditioning information, Journal of Finance, 967-982.

Ferson, W.E. and A.F. Siegel, 2009, Testing portfolio efficiency with conditioning information, Review of Financial Studies, 22, 2735-2758.

Fletcher, J, 2001, An examination of alternative factor models in UK stock returns, Review of Quantitative Finance and Accounting, 16, 117-130.

Fletcher, J., 2017, An empirical examination of the incremental contribution of stock characteristics in U.K. stock returns, International Journal of Financial Studies, 5, 1-19.

Frost, P.A. and J.E. Savarino, 1988, For better performance: Constrain portfolio weights, Journal of Portfolio Management, 15, 29-34.

Gagliardinia, P., Ossola, E. and O. Scaillet, 2016, Time-varying risk premium in large crosssectional equity datasets, Econometrica, 84, 985-1046. 
Gao, P. and K.X.D. Huang, 2008, Aggregate consumption-wealth ratio and the cross-section of stock returns: Some international evidence, Annals of Economics and Finance, 9, 1-37.

Gibbons, M.R., Ross, S.A. and J. Shanken, 1989, A test of the efficiency of a given portfolio, Econometrica, 57,1121-1152.

Grauer, R.R. and N.H. Hakansson, 1993, On the use of mean-variance and quadratic approximations in implementing dynamic investment strategies: A comparison of the returns and investment policies, Management Science, 39, 856-871.

Gregory, A. and M. Michou, 2009, Industry costs of equity: UK evidence, Journal of Business Finance and Accounting, 36, 679-704.

Gregory, A., Tharyan, R. and A. Christidis, 2013, Constructing and testing alternative versions of the Fama-French and Carhart models in the UK, Journal of Business Finance and Accounting, 40, 172214.

Gospodinov, N. and C. Robotti, 2013, Asset pricing theories, models, and tests, in Baker, H.K. and M.G. Filbeck (Eds), Portfolio Theory and Management, chapter 3, Oxford University Press.

Goyal, A., 2012, Empirical cross-sectional asset pricing: A survey, Financial Markets and Portfolio Management, 26, 3-38.

Hansen, L.P. and S.F. Richard, 1987, The role of conditioning information in deducing testable restrictions implied by dynamic asset pricing models, Econometrica, 55, 587-613.

Harvey, C.R., Liu, Y, and H. Zhu, 2016, ... and the cross-section of expected returns, Review of Financial Studies, 29, 5-68.

Harvey, C.R. and Y. Liu, 2018, Lucky factors, Working Paper, Duke University. Hodrick, R.J. and X. Zhang, 2014, International diversification revisited, Working Paper, University of Columbia. 
Hou, K., Xue, C. and L. Zhang, 2015, Digesting anomalies: An investment approach, Review of Financial Studies, 28, 650-705.

Jagannathan, R. and T. Ma, 2003, Risk reduction in large portfolios: Why imposing the wrong constraint helps, Journal of Finance, 58, 1651-1683.

Jegadeesh, N., Noh, J., Pukthuanthong, K., Roll, R. and J.L. Wang, 2017, Empirical tests of asset pricing models with individual assets: Resolving the errors-in-variables bias in risk premium estimation, Working Paper, Emory University.

Jegadeesh, N. and S. Titman, 1993, Returns to buying winners and selling losers: Implications for stock market efficiency, Journal of Finance, 48, 65-92.

Kan, R. and C. Robotti, 2012, Evaluation of asset pricing models using two-pass cross-sectional regressions, in J.C. Duan (Eds), Handbook of Computational Finance, 223-251.

Kim, S. and G. Skoulakis, 2018, Ex-post risk premia estimation and asset pricing tests using large cross sections: The regression calibration approach, Journal of Econometrics, forthcoming.

Kozak, S., Nagel, S. and S. Santosh, 2017, Interpreting factor models, Journal of Finance, forthcoming.

Lewellen, J., 2015, The cross-section of expected stock returns, Critical Finance Review, 4, 1-44.

Lewellen, J., Nagel, S. and J. Shanken, 2010, A skeptical appraisal of asset-pricing tests, Journal of Financial Economics, 96, 175-194.

Li, K., Sarkar, A. and Z. Wang, 2003, Diversification benefits of emerging markets subject to portfolio constraints, Journal of Empirical Finance, 10, 57-80.

Lin, X. and L. Zhang, 2013, The investment manifesto, Journal of Monetary Economics, 60, 351166. 
Lintner, J., 1965, The valuation of risk assets and the selection of risk investments in stock portfolios and capital budgets, Review of Economics and Statistics, 47, 13-37.

Liu, E.X., 2016, Portfolio diversification and international corporate bonds, Journal of Financial and Quantitative Analysis, 51, 959-983.

Liu, W. and N. Strong, 2008, Biases in decomposing holding period portfolio returns, Review of Financial Studies, 21, 2243-2274.

Lo, A. and A.C. MacKinlay, 1990, Data-snooping biases in tests of financial asset pricing models, Review of Financial Studies, 3, 431-468.

Maio, P. and P. Santa-Clara, 2012, Multifactor models and their consistency with the ICAPM, Journal of Financial Economics, 106, 586-613.

Mossin, J., 1966, Equilibrium in a capital asset market, Econometrica, 34, 768-783.

Nagel, S., 2013, Empirical cross-sectional asset pricing, Annual Review of Financial Economics, 5, 167-199.

Novy-Marx, R., 2012, The other side of value: The gross profitability premium, Journal of Financial Economics, 108, 1-28.

Penaranda, F., 2016, Understanding portfolio efficiency with conditioning information, Journal of Financial and Quantitative Analysis, 51, 985-1011

Plyakha, Y., Uppal, R. and G. Vilkov, 2016, Equal or value weighting? Implications for asset-pricing tests, Working Paper, Edhec.

Raponi, V., Robotti, C. and P. Zaffaroni, 2017, Testing beta-pricing models using large crosssections, Working Paper, Imperial College London. 
Sarisoy, C., de Goeij, P. and B.J.M. Werker, 2017, Linear factor models and the estimation of expected returns, Academic Paper, Netspar.

Shanken, J., 1990, Intertemporal asset pricing: An empirical investigation, Journal of Econometrics, 45, 99-120.

Shanken, J., 1992, On the estimation of beta-pricing models, Review of Financial Studies, 5, 1-33.

Sharpe, W.F., 1964, Capital asset prices: A theory of market equilibrium under conditions of risk, Journal of Finance, 19, 425-442.

Sharpe, W.F., 1966, Mutual fund performance, Journal of Business 39, 119-138.

Shumway, Tyler, 1997, The delisting bias in CRSP data, Journal of Finance 52, 327-340.

Stambaugh, R.F. and Y. Yuan, 2017, Mispricing factors, Review of Financial Studies, 30, 12701315.

Strong, N. and X. Xu, 1997, Explaining the cross-section of U.K. expected stock returns, British Accounting Review, 29, 1-23.

Subrahmanyam, A., 2010, The cross-section of expected stock returns: What have we learnt from the past twenty-five years of research?, European Financial Management, 16, 27-42.

Sun, L., Wei, K.C.J., and F. Xie, 2014, On the explanations of the gross profitability effect: Insights from international equity markets, Working Paper, Hong Kong University of Science and Technology.

Tu, J. and G. Zhou, 2011, Markowitz meets Talmud: A combination of sophisticated and naïve diversification strategies, 99, 204-215.

Wang, Z., 1998, Efficiency loss and constraints on portfolio holdings, Journal of Financial Economics, 48, 359-375.

Zellner, A., 1971, An introduction to Bayesian inference in econometrics (Wiley, New York). 